\title{
The Impact of Different Government Subsidy Methods on Low-Carbon Emission Reduction Strategies in Dual-Channel Supply Chain
}

\author{
Cheng Che, Yi Chen $\mathbb{D}$, Xiaoguang Zhang, and Zhihong Zhang $\mathbb{C}$ \\ School of Economics and Management, China University of Petroleum, Qingdao 266580, China \\ Correspondence should be addressed to Yi Chen; 934358114@qq.com
}

Received 5 November 2020; Revised 30 November 2020; Accepted 28 December 2020; Published 12 January 2021

Academic Editor: Wei Zhang

Copyright (c) 2021 Cheng Che et al. This is an open access article distributed under the Creative Commons Attribution License, which permits unrestricted use, distribution, and reproduction in any medium, provided the original work is properly cited.

\begin{abstract}
With the implementation of national carbon emission reduction policies and the development of online shopping, manufacturers are making low-carbon efforts and selling products through dual channels. This paper constructs a dual-channel supply chain decision-making model composed of low-carbon emission reduction manufacturers and retailers and studies the optimal decision-making problem of the supply chain under subsidies by the government based on emission reduction R\&D and per unit product emission reduction. The research results show the following: (1) when the government subsidizes emission reduction R\&D, the emission reduction will have an impact on retailers' optimal prices, manufacturers' optimal wholesale prices, and optimal direct sales channel sales prices. The profit of the manufacturer increases with the increase in carbon emissions, and the profit of the manufacturer increases to a certain level and then appears to decline. (2) When the government adopts a subsidy method based on the emission reduction per unit product, the manufacturer's wholesale price and the selling price of direct sales channels, as well as the retailer's own optimal price, will increase with the increase in emission reductions. Retailers' profits will increase linearly with the increase in carbon emissions. Manufacturers' profits will first increase in a straight line and then increase in a curve.
\end{abstract}

\section{Introduction}

Nowadays, China is facing environmental pollution problems, and lots of Chinese cities have encountered smog pollution and extreme high PM2.5 [1]. China proposed in 2016 that carbon dioxide emissions per unit of GDP will be reduced by $60 \%-65 \%$ by 2030 compared to 2005 [2]. In order to curb the growth of carbon emissions and complete the energy development strategy action plan, the Chinese government has promulgated many policies to increase the enthusiasm of enterprises to reduce carbon emissions, such as subsidies, tax incentives, and government priority procurement. Among them, government subsidies are considered to be generally effective policies [3].

These measures indicate the necessity for enterprises to change the traditional economic development model, and low-carbon development model is the future economic development trend. Under this environmental and policy background, companies are under external pressure to carry out green and low-carbon activities and invest in low-carbon $\mathrm{R} \& \mathrm{D}$ in the production process to improve production technology and reduce carbon emissions in the production process [4]. Some large companies actively take new actions and even reduce carbon emissions through innovative research and development to show their social responsibility and enhance their public image and reputation.

Furthermore, in the context of the rapid development of e-commerce and mobile Internet, consumer shopping behavior is shifting to online shopping, prompting manufacturers to maintain traditional retail channels while opening up online sales channels and directly obtain market information to occupy more market shares. Manufacturers provide the same low-carbon products for retail channels and online sales channels in the dual-channel supply chain. 
Due to factors such as product pricing and shopping convenience, the online sales channels opened by manufacturers will inevitably cause conflicts and competition between channels. They will cause problems that damage the profits of retailers or reduce the low-carbon efforts of manufacturers and change the cooperative relationship between upstream and downstream enterprises in the supply chain [5].

Nevertheless, due to different subsidy methods, the effects of subsidies are different. Based on the above situation, this paper will consider the dual-channel supply chain of low-carbon emission reduction under different government subsidies and try to explore how to make different emission reduction decisions under different government subsidies for manufacturers to obtain greater benefits and different energy conservation and emission reduction effects produced by different government subsidies.

\section{Literature Review}

The research related to this paper mainly focuses on three aspects: government subsidies, low-carbon supply chain, and dual-channel supply chain. Therefore, this section will summarize the above three parts.

2.1. Low-Carbon Supply Chain. In recent years, there are many literature studies about low-carbon supply chain. In terms of product pricing strategy and profit, Huang et al. found that fairness preferences changed retail prices, wholesale prices, greenness levels, and scrap recycling rates, and it affects the profit and utility of manufacturers and distributors as well as the total profit of supply chain $[6,7]$. In addition, Madani and Rasti-Barzoki also analyzed the pricing and emission reduction strategies of the supply chain. They developed a competitive mathematical model of government as the leader and two competitive green and nongreen supply chains as the followers [8]. In terms of supply chain coordination, Liu and Yi discussed the coordination and cooperation mechanism between manufacturers and retailers when demand is affected by product greenness [9]. Zhang et al., Basiri, and Heydari analyzed the impact of consumer environmental awareness and product greenness on supply chain coordination $[10,11]$. In terms of emission reduction strategies, by constructing a cooperative emission reduction income distribution plan, Wang et al. gave the emission reduction income distribution coefficient in the region and initial income distribution matrix of every subject, in order to improve various entities' cooperation to reduce emissions [12]. Wang et al. investigated a fresh food supply chain comprising a large-scale supplier and multiple small-scale retailers. They researched retailers' joint replenishment and supply chain members' carbon trading behavior [13]. Under the secondary supply chain consisting of a risk-averse manufacturer and a risk-averse retailer, Bai et al. have established a retail-led and manufacturer-led supply chain model under the constraints of low-carbon emission reduction [14]. Chen et al. considered the dualinformation asymmetry of the enterprise's emission reduction technology level and emission reduction capital investment and study the design of enterprise emission reduction incentive contracts [15]. Xu et al. proposed a multiobjective optimization model to solve the dynamic vehicle routing problem with limited supply in oil distribution and found that the variable neighborhood dynamic vehicle planning model is superior to other comparable schemes in terms of cost saving and satisfaction improvement $[16,17]$. Xu et al. proposed a model which can effectively utilize the fuzzy resources in collaborative logistics network and avoid the resource shortage problem caused by excessive occupation of local resources $[18,19]$.

2.2. Dual-Channel Supply Chain. Channel coordination can make the operation of the supply chain more efficient, and channel members can benefit from it. As a result, scholars have carried out a lot of research on the coordination of dual-channel supply chain. Li et al. studied the coordination strategies of different supply chain entities in a supply chain composed of recyclers, remanufacturers, and two distributors and discussed four different coordination strategies and performed optimal decisions on different models [20]. Pu et al. found that consumers' free riding has a certain impact on the sales effect of dual-channel supply chain and proposed a cost sharing contract to achieve the coordination between them [21]. Xu et al. considered carbon allowances, carbon trading system, and consumer channel preferences, studied the impact of channel substitution on pricing and carbon emission reduction strategies, and encouraged retailers to share their revenue and cost by cutting the wholesale price so as to realize supply chain coordination [22]. Zhou considered the initial demand of physical channels and online channels and studied the supply chain channel structure selection strategy based on the relative rate of customer channel preference between manufacturers and physical retailers as decision makers [23]. Based on the differences in the game power of supply-chain members, Sun et al. constructed two types of Stackelberg games where the manufacturer dominated or the retailer dominated and the Nash game model where both parties have equal power and analyzed the impact of the three game power structures on supply chain members [24]. Wang et al. solved the optimal decision-making problem of the manufacturer and retailer under wholesale price contract and revenue sharing contract by constructing a two-channel supply chain game model [25]. Liang and Wei established a dual-channel supply chain decision-making model consisting of manufacturers and retailers with input innovation and studied the influence of government's simultaneous use of R\&D subsidies and production subsidies on supply chain innovation, pricing, and profit [26].

2.3. Government Subsidies. Another closely related literature stream is government subsidies. Maria et al. pointed out that government $\mathrm{R} \& \mathrm{D}$ subsidies can promote enterprise $\mathrm{R} \& \mathrm{D}$ investment [27]. Michalsen found that when the downstream market is highly concentrated, the government provides the best $\mathrm{R} \& \mathrm{D}$ subsidy strategy. In other cases, 
providing tax incentives is the optimal strategy [28]. Tong and Li found that both green manufacturers and retailers can benefit from government subsidies and green cost sharing contracts, but they are related to R\&D cost coefficients, green sensitivity coefficients, and price sensitivity coefficients $[29,30]$. Nielsen et al. found that when manufacturers set a green degree, compared with the government's incentive policies for R\&D, supply chain members will obtain higher profits at lower sales prices, higher consumer surplus, and improved environment [31, 32]. He et al. considered the two scenarios of manufacturers' independent research and development of emission reduction and outsourcing emission reduction tasks and studied the optimal decision-making problem of the supply chain under the government subsidies based on emission reduction research and development and unit product emission reduction $[33,34]$. Based on the two recycling modes, Xia and Zhu constructed the game model of recyclers and processors under different government subsidy strategies, compared and analyzed the influence of government subsidies on the decision variables, recycling quantity, and revenue of recycling channels, and determined the boundary conditions of the optimal recycling model $[35,36]$. Zu et al. analyzed the impact of consumers' environmental awareness on profits and decision-making in different situations. Their research results showed that under centralized decision-making, an increase in the carbon tax rate will increase the low-carbon level of products and reduce the present value of profits in the supply chain. In order to mobilize the enthusiasm of enterprises to reduce emissions, the government can take into account the environmental objectives and the interests of enterprises to formulate a reasonable carbon tax policy $[37,38]$.

By reviewing the above literature, we can find that scholars have lots of studies on low-carbon supply chains and obtained many research results. We can see that the existing research on low-carbon supply chain is mostly from the perspective of product pricing, supplier cooperation, and corporate emission reduction strategies. For the dual-channel supply chain generated under the background of the Internet, the existing research mostly starts from the perspectives of supplier optimal decision-making, supplier power structure, and supplier cooperation in reducing emissions. In addition, in order to promote enterprises to actively participate in emission reduction activities, the Chinese government has introduced many subsidy policies in recent years. Existing studies on government subsidies are mostly based on the impact of subsidy policies on enterprises' participation in emission reduction and the game relationship between the government and enterprises. However, the research on dualchannel supply chain is still in its infancy. The existing literature rarely combines dual-channel supply chains with government subsidies, and there are fewer studies considering the differences in government subsidies. On the basis of the existing research and different from the literature above, we try to construct a dual-channel supply chain decision-making model composed of low-carbon emission reduction manufacturers and retailers and analyze the impact of different government subsidies on manufacturers and retailers in the dual-channel supply chain.

\section{Problem Description and Model Hypotheses}

So as to research the emission reduction strategies of the manufacturer's dual-channel supply chain under different government subsidies, this paper establishes a dual-channel supply chain model which is shown in Figure 1 consisting of a retailer and a manufacturer. The government can decide to subsidize manufacturers based on two different subsidy methods: emission reduction per unit product or emission reduction $R \& D$ investment. At the same time, manufacturers wholesale products to retailers through traditional channels on the one hand and sell products directly to the market through online channels, forming a dual-channel supply chain.

Assumption 1. Because market demand is negatively correlated with sales price and positively correlated with product low-carbon attributes and there is a price competition between channels, this paper refers to the channel demand function established by Li et al. [39] to set the demand function of traditional retail channels and online sales channels.

They are

$$
\begin{gathered}
D_{r}=\theta A-p_{i}^{r}+\beta p_{i}^{m}+k e_{i}, \\
D_{m}=(1-\theta) A-p_{i}^{m}+\beta p_{i}^{r}+k e_{i},
\end{gathered}
$$

where $D_{r}$ represents the demand of traditional retail channels, $D_{m}$ represents the demand of online direct sales channels, $\mathrm{A}$ is the potential market size, $\theta(0 \leq \theta \leq 1)$ is the market share occupied by traditional channels, $1-\theta$ is the market occupied by direct sales channels share, $p_{i}^{r}$ is the product price in the traditional retail channel under the $i$ subsidy method, $p_{i}^{m}$ is the product price in the $i$-subsidy network direct sales channel, $\beta$ represents the cross-price elasticity coefficient of the traditional channel and the direct sales channel $(0<\beta<1), k$ represents the level of consumer environmental awareness $(0<k<1)$, and $e_{i}$ represents the emission reduction per unit product under the $i$-subsidy method.

Assumption 2. The manufacturer's unit manufacturing cost remains unchanged, and the raw material procurement cost is the main factor. Other costs such as equipment and manpower are not considered for the time being. When increasing investment in emission reduction $R \& D$, the cost of carbon emission reduction R\&D investment and emission reduction are quadratic [40]. The manufacturer's carbon emission reduction $\mathrm{R} \& \mathrm{D}$ cost is $(1 / 2) I e_{i}^{2}$, where $I$ represents the manufacturer's emission reduction $\mathrm{R} \& \mathrm{D}$ cost coefficient.

Assumption 3. In order to promote manufacturers to reduce carbon emissions, the government will give manufacturers certain financial subsidies. Assume that the government subsidizes manufacturers in two forms [41]: firstly, subsidies are based on the manufacturer's emission reduction per unit product. The government's subsidy expenditure for emission reduction per unit product is $\lambda e_{1}$, where $\lambda$ is the emission 


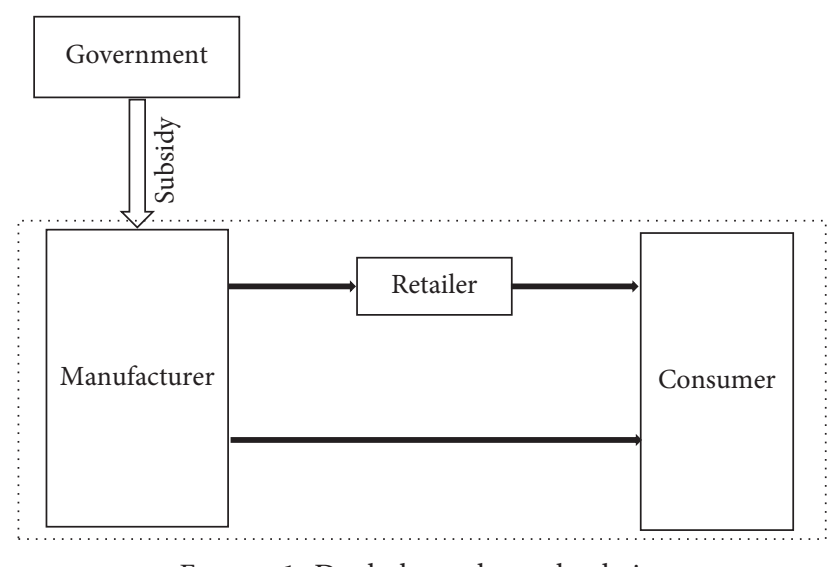

FIGURE 1: Dual-channel supply chain.

reduction subsidy coefficient per unit product; secondly, some subsidies are given according to the manufacturers' $\mathrm{R} \& \mathrm{D}$ investment. According to the expression of carbon emission reduction $\mathrm{R} \& \mathrm{D}$ investment, the total government $\mathrm{R} \& \mathrm{D}$ investment subsidy expenditure is $t e_{2}^{2}$, where $t$ is the R\&D subsidy coefficient of emission reduction.

Assumption 4. In the supply chain game model of this paper, the game sequence is that the government first determines the subsidy method, then the manufacturer determines the emission reduction $e_{i}$, the wholesale price $w_{i}$, and the direct sales price $p_{i}^{m}$, and finally the retailer determines the traditional channel sales price $p_{i}^{r}$, as shown in Figure 2 .

All the parameters and their definitions involved in this paper are summarized in Table 1.

\section{Model Analysis}

4.1. Situation 1: under the Subsidy Method of Emission Reduction per Unit Product. In this situation, government subsidizes emission reductions per unit product and manufacturers choose to independently research and develop emission reductions. The profits of the manufacturer $\left(\pi_{1}^{\mathrm{m}}\right)$ and the retailer $\left(\pi_{1}^{r}\right)$ are

$$
\begin{aligned}
\pi_{1}^{\mathrm{m}} & =\mathrm{w}_{1} \mathrm{D}_{\mathrm{r}}+p_{1}^{m} \mathrm{D}_{\mathrm{m}}+\lambda e_{1}\left(D_{\mathrm{r}}+D_{\mathrm{m}}\right)-\frac{1}{2} I \mathrm{e}_{1}^{2}, \\
\pi_{1}^{r} & =\left(p_{1}^{r}-w_{1}\right) D_{r},
\end{aligned}
$$

where $w_{1}$ is the wholesale and retail price set by the manufacturer under the government's subsidy per unit of product emission reduction. After substituting equations (1) and (2) into equations (3) and (4), the decision model for both parties is

$$
\begin{aligned}
\max _{e_{1} w_{1} p_{1}^{m}} \pi_{1}^{\mathrm{m}}= & \mathrm{w}_{1} \theta A-p_{1}^{r}+\beta p_{1}^{m}+k e_{1} \\
& +p_{1}^{m}\left[(1-\theta) A-p_{1}^{m}+\beta p_{1}^{r}+k e_{1}\right], \\
\max _{p_{1}^{r}} \pi_{1}^{r}= & \left(p_{1}^{r}-w_{1}\right)\left(\theta A-p_{1}^{r}+\beta p_{1}^{m}+k e_{1}\right) .
\end{aligned}
$$

It is solved by the inverse induction method: first, $N \pi_{1}^{r}$ finds the second derivative with respect to $p_{1}^{r}$ and get $\left(\partial^{2} N \pi_{1}^{r} / \partial p_{1}^{r 2}\right)=-2<0$. So, there is an optimal solution for the strict concave function of $p_{1}^{r}$, and then by finding the first derivative of $\pi_{1}^{r}$ with respect to $p_{1}^{r}$ and making it equal to 0 , we get $p_{1}^{r}$ with respect to $e_{1}$, the optimal response function of $w_{1}$ and $p_{1}^{m}$ :

$$
\begin{aligned}
\frac{\partial \pi_{1}^{r}}{\partial p_{1}^{r}} & =\theta A-2 p_{1}^{r}+\beta p_{1}^{m}+k e_{1}+w_{1}, \\
p_{1}^{r}\left(e_{1}, w_{1}, p_{1}^{m}\right) & =\frac{\theta A+\beta p_{1}^{m}+k e_{1}+w_{1}}{2} .
\end{aligned}
$$

Property 1. Under the subsidy mode of emission reduction per unit product, the retailer's optimal price response function is an increasing function of $e_{1} w_{1}$ and $p_{1}^{m}$.

This property indicates that in this case, manufacturers' increasing emission reductions and increasing product wholesale prices or direct sales channel prices will all cause retailers to increase traditional channel sales prices, thereby increasing the marginal revenue per unit product.

Then, substitute (6) into (5) to obtain

$$
\begin{gathered}
\frac{\partial^{2} \pi_{1}^{\mathrm{m}}}{\partial w_{1}^{2}}=-1, \\
\frac{\partial^{2} \pi_{1}^{\mathrm{m}}}{\partial p_{1}^{m 2}}=\beta^{2}-2, \\
\frac{\partial^{2} \pi_{1}^{\mathrm{m}}}{\partial w_{1} p_{1}^{m}}=\beta, \\
\frac{\partial^{2} \pi_{1}^{\mathrm{m}}}{\partial p_{1}^{m} w_{1}}=\beta .
\end{gathered}
$$

From this, the Hessian matrix of the manufacturer's profit function with respect to $w_{11}$ and $p_{11}^{m}$ is as follows:

$$
H\left(\pi_{1}^{\mathrm{m}}\right)=\left[\begin{array}{cc}
-1 & \beta \\
\beta & \beta^{2}-2
\end{array}\right] \text {. }
$$




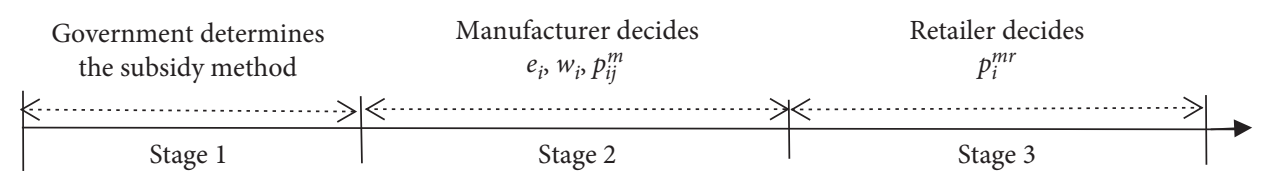

Figure 2: Decision sequence diagram.

TABLe 1: Notations.

\begin{tabular}{lc}
\hline Parameters & Definition \\
\hline$D_{r}$ & Demand of traditional retail channels \\
$D_{m}$ & Demand of online sales channels \\
$A$ & Market scale \\
$\theta$ & Market share of traditional retail channels \\
$p_{i}^{r}$ & Product price of traditional retail channels \\
$p_{i}^{m}$ & Product price of online sales channels \\
$\beta$ & Cross-price elasticity factor \\
$k$ & Consumer environmental awareness level \\
$e_{i}$ & Emission reduction \\
$I$ & Manufacturer's emission reduction R\&D cost \\
$\lambda$ & coefficient \\
$t$ & Subsidy coefficient of emission reduction per unit \\
$w_{i}$ & product \\
\hline
\end{tabular}

The first-order principal subformula in this matrix is negative, $\left|H\left(\pi_{1}^{\mathrm{m}}\right)\right|=2\left(1-\beta^{2}\right)>0$, so the manufacturer's profit function is a strictly joint concave function of $\mathrm{w}_{1}$ and $\mathrm{p}_{11}^{\mathrm{m}}$, the objective function. There is an optimal solution. Take the manufacturer's profit function (5) to derive $w_{1}$ and $p_{11}^{m}$ and set them equal to 0 . After the combination, the optimal inverse function of $e_{1}$ can be obtained:

$$
\begin{array}{r}
\frac{\partial \pi_{1}^{\mathrm{m}}}{\partial w_{1}}=\frac{1}{2} \theta A+\frac{k e_{1}}{2}-w_{1}+\beta p_{1}^{m}+\frac{(\beta-1) \lambda e_{1}}{2}, \\
\frac{\partial \pi_{1}^{\mathrm{m}}}{\partial p_{1}^{m}}=\beta w_{1}+\left(1-\theta+\frac{\beta \theta}{2}\right) A+\left(\beta^{2}-2\right) p_{1}^{m} \\
+\frac{k \beta+2 k+\lambda \beta^{2}+\lambda \beta-2 \lambda}{2} e_{1}, \\
w_{1}^{*}\left(e_{1}\right)=\frac{k \beta+k-\lambda+\lambda \beta^{2}}{2-2 \beta^{2}} e_{1}+\frac{\theta A}{2}+\frac{A \beta(1-\theta+\beta \theta)}{2-2 \beta^{2}} \\
\mathrm{p}_{1}^{\mathrm{m} *}\left(e_{1}\right)=\frac{k \beta+\mathrm{k}-\lambda+\lambda \beta^{2}}{2-2 \beta^{2}} e_{1}+\frac{(1-\theta+\beta \theta) A}{2-2 \beta^{2}} .
\end{array}
$$

Substitute (10) and (11) into (6) to obtain the optimal response function of $p_{11}^{r}$ with respect to $e_{1}$ :

$$
\begin{aligned}
p_{1}^{r *}\left(e_{1}\right) & =\frac{\beta q_{1}+k+q_{1}}{2} e_{1}+\frac{3}{4} \theta A+\beta q_{2}, \\
q_{2} & =\frac{A(1-\theta+\beta \theta)}{2-2 \beta^{2}} .
\end{aligned}
$$

In order to judge the linear relationship between $p_{1}^{m *}, w_{1}^{*}, p_{1}^{r *}$, and $e_{1}$, we further sort out (10), (11), and (12) to obtain the following equations for $e_{1}$ :

$$
\begin{aligned}
w_{1}^{*}\left(e_{1}\right)= & \frac{k+\lambda(\beta-1)}{2(1-\beta)} e_{1}+\frac{\theta A}{2}+\frac{A \beta(1-\theta+\beta \theta)}{2-2 \beta^{2}}, \\
\mathrm{p}_{1}^{\mathrm{m} *}\left(e_{1}\right)= & \frac{k+\lambda(\beta-1)}{2(1-\beta)} e_{1}+\frac{(1-\theta+\beta \theta) A}{2-2 \beta^{2}}, \\
p_{1}^{r *}= & \frac{\left(-\beta^{3}-\beta^{2}+\beta+1\right) \lambda+\left(3 \beta^{2}+2 \beta-1\right) k}{4 \beta^{2}-4} e_{1} \\
& +\frac{\left(\beta^{2} \theta+2 \beta \theta-3 \theta-2 \beta\right) A}{4 \beta^{2}-4} .
\end{aligned}
$$

The coefficients of $w_{1}^{*}\left(e_{1}\right), \mathrm{p}_{1}^{\mathrm{m} *}\left(e_{1}\right)$ are $(k+\lambda(\beta-1) /$ $2(1-\beta))$, because $0<\beta<1$, so we cannot judge directly whether the function is increasing or decreasing, and the impact of emission reductions on wholesale prices and direct sales channel sales prices will vary with the changes of $k, \beta$, and $\lambda$.

Property 2. Under the subsidy method of emission reduction per unit product, $e_{1}$ has an impact on the retailer's optimal price $p_{1}^{r *}$, the optimal wholesale price $w_{1}^{*}$, and the optimal direct sales channel sales price $p_{1}^{m}$, and changes with the level of consumer environmental awareness, the crossprice elasticity coefficient of the dual channel, and the emission reduction subsidy coefficient per unit product.

4.2. Situation 2: under the Mode of R\&D Subsidy for Emission Reduction. When the government adopts the subsidy mode of emission reduction research and development, the manufacturer $\left(\pi_{2}^{\mathrm{m}}\right)$ and retailers $\left(\pi_{2}^{r}\right)$ are as follows:

$$
\begin{aligned}
\max _{e_{2} w_{2} p_{2}^{m}} \pi_{2}^{\mathrm{m}}= & \mathrm{w}_{2} \theta A-p_{2}^{r}+\beta p_{2}^{m}+k e_{2} \\
& +p_{2}^{m}\left[(1-\theta) A-p_{2}^{m}+\beta p_{2}^{r}+k e_{2}\right] \\
& +t e_{2}^{2}-\frac{1}{2} I e_{2}^{2}, \\
\max _{p_{2}^{r}} \pi_{12}^{r}= & \left(p_{2}^{r}-w_{2}\right)\left(\theta A-p_{2}^{r}+\beta p_{2}^{m}+k e_{2}\right) .
\end{aligned}
$$

The inverse induction method is used to solve the problem, and first of all, $N \pi_{2}^{r}$ calculates the second derivative of $p_{2}^{r}$ and obtains $\left(\partial^{2} N \pi_{2}^{r} / \partial p_{2}^{r 2}\right)=-2<0$. So, $N \pi_{2}^{r}$ is about 
$p_{2}^{r}$ which is a strictly concave function, and there is an optimal solution. And then by finding $\pi_{2}^{r}$ about $p_{2}^{r}$, the first derivative is equal to 0 , and then we get the optimal response function of $p_{2}^{r}$ about $e_{2}, w_{2}, p_{2}^{m}$ :

$$
\begin{aligned}
\frac{\partial \pi_{2}^{r}}{\partial p_{2}^{r}} & =\theta A-2 p_{2}^{r}+\beta p_{2}^{m}+k e_{2}+w_{2}, \\
p_{2}^{r}\left(e_{2}, w_{2}, p_{2}^{m}\right) & =\frac{\theta A+\beta p_{2}^{m}+k e_{2}+w_{2}}{2} .
\end{aligned}
$$

Property 3. Under the R\&D subsidy, the retailer's optimal price response function is about $e_{2}, w_{2}, p_{2}^{m}$, the increasing function.

This property shows that in this case, the manufacturer's increase of emission reduction and the increase of wholesale price or direct channel price will make the retailer increase the price of traditional channel, thus increasing the marginal revenue of unit product.

Then, equation (15) is substituted into equation (13) to obtain

$$
\begin{gathered}
\frac{\partial^{2} \pi_{2}^{\mathrm{m}}}{\partial w_{2}^{2}}=-1, \\
\frac{\partial^{2} \pi_{2}^{\mathrm{m}}}{\partial p_{2}^{m 2}}=\beta^{2}-2, \\
\frac{\partial^{2} \pi_{2}^{\mathrm{m}}}{\partial w_{2} p_{2}^{m}}=\beta, \\
\frac{\partial^{2} \pi_{2}^{\mathrm{m}}}{\partial p_{2}^{m} w_{2}}=\beta .
\end{gathered}
$$

Thus, regarding the profit function of the manufacturer with respect to $w_{11}, p_{11}^{m}$, the Hessian matrix is

$$
H\left(\pi_{2}^{\mathrm{m}}\right)=\left[\begin{array}{cc}
-1 & \beta \\
\beta & \beta^{2}-2
\end{array}\right] .
$$

In this matrix, the first principal subexpression is negative, $\left|H\left(\pi_{2}^{\mathrm{m}}\right)\right|=2\left(1-\beta^{2}\right)>0$, so the manufacturer's profit function is about $w_{2}$ and $p_{2}^{m}$. In this paper, the manufacturer's profit function formula (5) is applied to $p_{2}^{m}$ and $\mathrm{w}_{2}$ and makes it equal to 0 ; then, the optimal inverse function of $e_{2}$ can be obtained:

$$
\begin{aligned}
& \frac{\partial \pi_{2}^{m}}{\partial w_{2}}=\frac{1}{2} \theta A+\frac{k e_{2}}{2}-w_{2}+\beta p_{2}^{m} \\
& \frac{\partial \pi_{2}^{\mathrm{m}}}{\partial p_{2}^{m}}=\beta w_{2}+\left(1-\theta+\frac{\beta \theta}{2}\right) A+\left(\beta^{2}-2\right) p_{2}^{m}+\frac{k \beta+2 k}{2} e_{2} \\
& w_{2}^{*}\left(e_{2}\right)=\frac{k}{2-2 \beta} e_{2}+\frac{A(\theta+\beta-\beta \theta)}{2-2 \beta^{2}}
\end{aligned}
$$

$$
p_{2}^{\mathrm{m} *}\left(e_{2}\right)=\frac{\mathrm{k}}{2-2 \beta^{2}} e_{2}+\frac{(1-\theta+\beta \theta) A}{2-2 \beta^{2}} .
$$

Substituting (16) and (17) into (15) yields $p_{2}^{r}$ about $e_{2}$, and the optimal response function is

$$
p_{2}^{r *}\left(e_{2}\right)=\frac{k(3-\beta)}{4-4 \beta} e_{2}+\frac{A\left(\theta-4 \theta \beta+2 \beta+\theta \beta^{2}\right)}{4-4 \beta^{2}} .
$$

Further judgment $\mathrm{p}_{2}^{\mathrm{m} *}, w_{2}^{*}, p_{2}^{r *}$, and $e_{2}$, that is, to judge the positive and negative of $(k / 2-2 \beta)$, because $0<\beta<1$, $0<k<1$, and the following property can be assumed.

Property 4. Under the $\mathrm{R} \& \mathrm{D}$ subsidy, the retailer's optimal price response function, $w_{2}, p_{2}^{m}$ are the increasing functions of $e_{2}$.

This property shows that when the government determines the subsidy mode of $\mathrm{R} \& \mathrm{D}$ according to emission reduction, the manufacturer's wholesale price for traditional channels and sales price for direct sales channel, as well as the retailer's optimal price, will increase with the increase of emission reduction.

\section{Numerical Simulation}

In the following, numerical simulation will be used to simulate the impact of emission reductions per unit of product on manufacturers' wholesale prices, profits, sales prices of the dual channel, and retailers' profits under different government subsidies. Refer to previous related papers [42-44], and set the corresponding parameter value:

$$
\begin{aligned}
k & =0.5, \\
\beta & =0.5, \\
\lambda & =[4,8], \\
\theta & =0.6, \\
A & =1500, \\
I & =900, \\
t & =[200,400] .
\end{aligned}
$$

5.1. The Impact of Emission Reduction on Wholesale Price under Different Subsidies. In the two cases of government subsidies based on R\&D and unit quantity, the optimal wholesale price, that is, formulas (13) and (22), is numerically simulated, as shown in Figure 3. It is verified once again that under the two subsidy methods, the optimal wholesale price of manufacturers to retailers will increase with the increase of carbon emissions.

5.2. The Impact of Emission Reductions under Different Subsidy Methods on the Sales Prices of the Dual Channel. In the two cases of government subsidies based on R\&D and unit quantity, the obtained optimal direct selling price and the optimal traditional retail wholesale price are calculated 


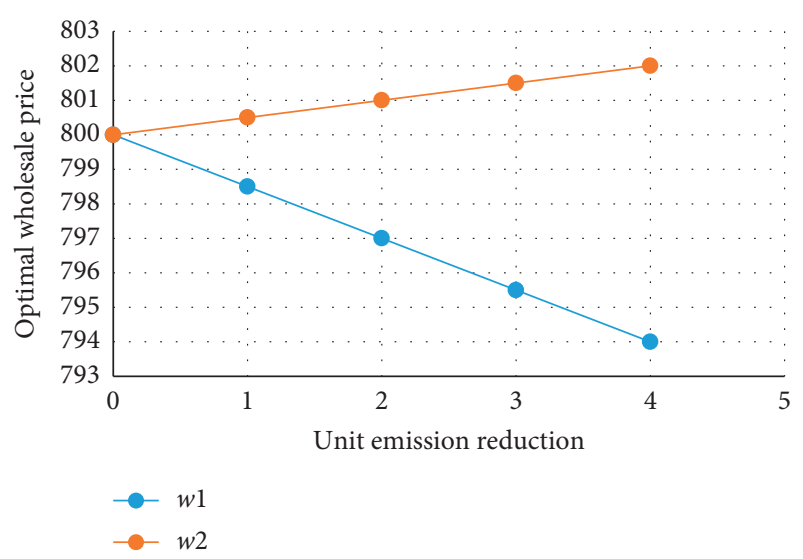

FIgURE 3: Wholesale price comparison chart.

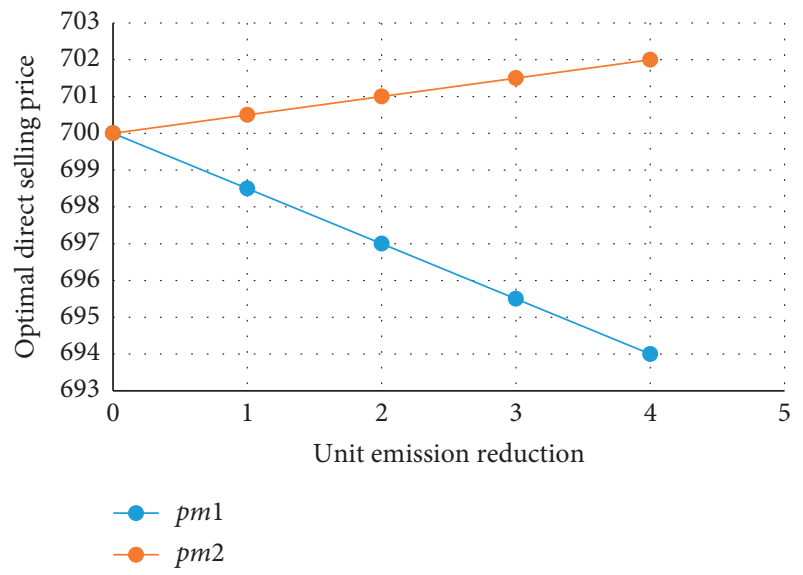

FIGURE 4: Direct selling price comparison chart.

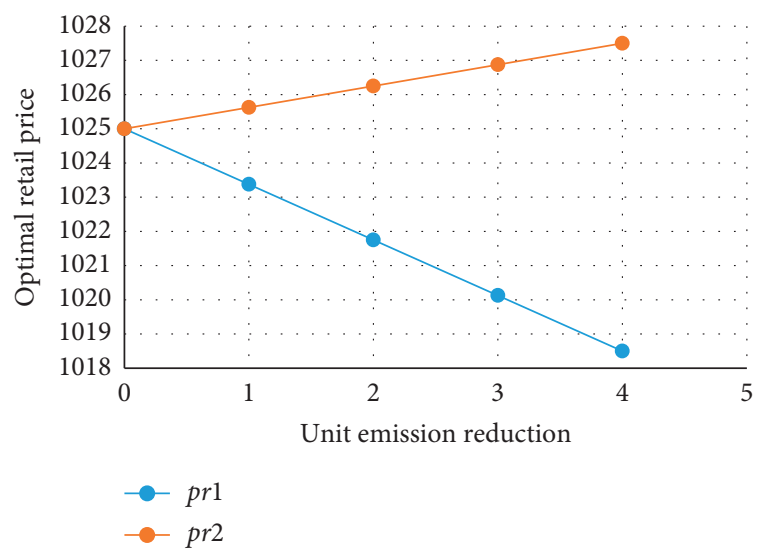

FIGURE 5: Retailer price comparison chart.

by formulas (14), (15), (23), and (24). The simulation is shown in Figures 4 and 5.

5.3. The Impact of Emission Reductions on the Profits of the Dual Channel under Different Subsidies. In the two cases of

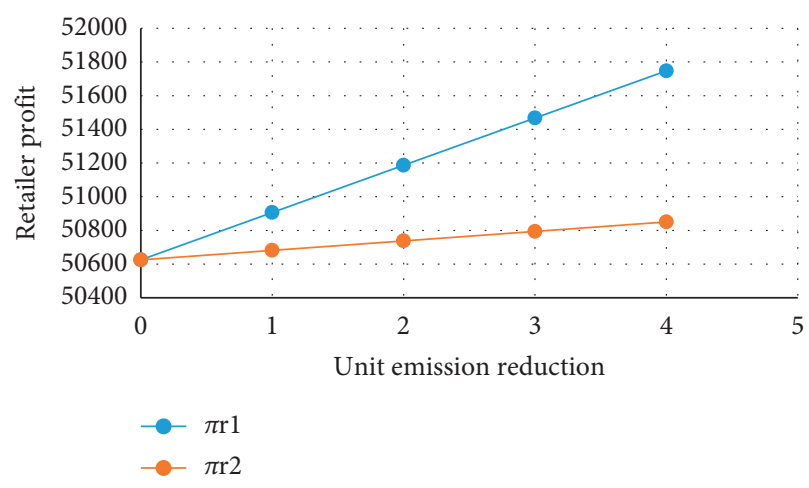

Figure 6: Manufacturer's profit comparison chart.

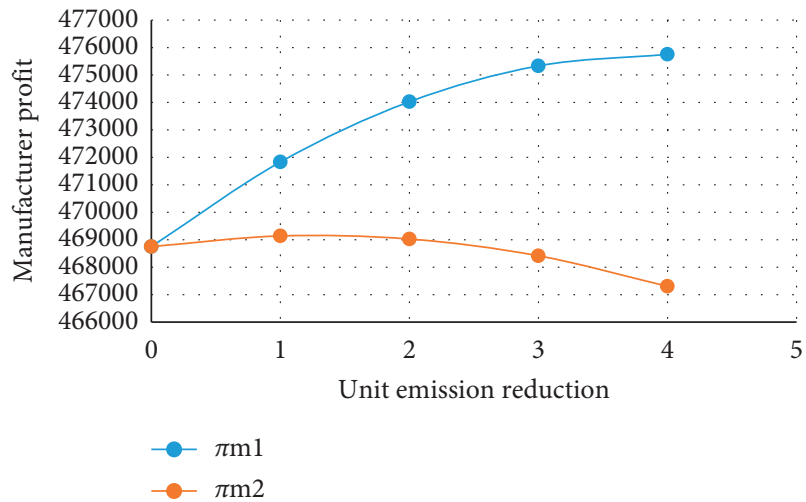

Figure 7: Retailer profit comparison chart.

government subsidies based on R\&D and unit quantity, the obtained optimal direct selling price and the optimal traditional retail wholesale price, namely, formulas (14), (15), (23), and (24), are calculated simulation, as shown in Figures 6 and 7.

\section{Conclusions and Discussion}

In this paper, we consider two different ways of government emission reduction, R\&D subsidies and subsidies per unit volume, establish a game model of green supply chain decision-making under different government subsidies, and analyze the impact of different subsidies on manufacturers and retailers.

The results show the following: (1) when the government subsidizes emission reduction research and development subsidies, emission reduction has an impact on the retailer's optimal price, the manufacturer's optimal wholesale price, and the optimal direct channel sales price, and changes with the consumer's environmental awareness level, the crossprice elasticity coefficient of the dual channel, and the emission reduction subsidy coefficient of unit product. (2) When the government adopts the subsidy method based on the emission reduction per unit product, after the manufacturer determines the emission reduction, the wholesale price of the manufacturer to the traditional channel and the sales price of the direct channel, and the optimal price of the 
retailer itself will increase with the increase of the emission reduction. (3) When the government subsidizes the emission reduction based on the research and development of emission reduction, the retailer's optimal price will increase with the increase of emission reduction. The profit increases with the increase of carbon emission, and the profit of manufacturers decreases after it increases to a certain extent. (4) When the government adopts the subsidy based on the emission reduction per unit product, under the optimal decision, the retailer's profit increases linearly with the increase of carbon emission, and the manufacturer's profit first increases linearly and then increases curvilinearly. The research results have important reference significance for the government to choose the subsidy mode for the manufacturer-led green supply chain and for the supply chain manufacturers to make emission reduction decisions in the face of government subsidies.

Therefore, the following management implications are put forward.

For the government, low-carbon emission reduction subsidies mobilize the enthusiasm of enterprises to participate in low-carbon sustainable development, and different subsidies have different effects on enterprises. In the face of different types and sizes of enterprises, enterprises should choose different ways of subsidies. For mature large enterprises, they can be encouraged to develop more lowcarbon emission reduction technologies, and small-scale enterprises can adopt the method of per unit emission reduction. In addition, we should cooperate with publicity and education to enhance consumers' awareness of environmental protection, guide consumers to buy low-carbon products, and increase the sales of green products in the whole market, so as to improve the profits of emission reduction enterprises and increase the overall social welfare.

For manufacturers, the emission reduction subsidies carried out by the government can effectively improve the overall profit of the supply chain and also promote the emission reduction level of enterprises. When the government grants R\&D subsidies for emission reduction, enterprises can choose to independently develop emission reduction technologies, which is conducive to the development of enterprises in the long run, but also need to consider their own business situation. For different types of enterprises, the measures should be different. In addition, we should pay attention to the decision-making of carbon emissions, which may affect the company's profits when the carbon emissions reach a certain level. Under the influence of low-carbon emission reduction, the dual-channel sales mode has a certain income risk, which needs to be further weighed.

There are several limitations in this research. Firstly, this paper does not consider that the manufacturers can choose their own R\&D and outsourcing R\&D to reduce emissions, because many enterprises have begun to hand over the lowcarbon emission reduction work to professional companies, and the cost and profit generated by this situation will be different from their own R\&D emission reduction technologies, and the corresponding emission reduction strategies will be different; secondly, in the process of the game, this paper does not consider retailers, and future research can explore how to achieve win-win cooperation between manufacturers and retailers under government subsidies.

\section{Data Availability}

The data used to support the findings of this study are available from the corresponding author upon request.

\section{Conflicts of Interest}

The authors declare that there are no conflicts of interest regarding the publication of this paper.

\section{Acknowledgments}

This research was funded by the Qingdao Social Science Planning Research Project (QDSKL1901037), the Fundamental Research Funds for the Central Universities (19CX04010B), and the Shandong Soft Science Research Program General Project (2020RKE28013).

\section{References}

[1] X. Li and B. Tilt, "Public engagements with smog in urban China: knowledge, trust, and action," Environmental Science \& Policy, vol. 92, no. 1, pp. 220-227, 2019.

[2] X. Y. Cao and X. Z. Wu, "Cooperative strategy for carbon emission reduction technology innovation in a dual-channel supply chain under the carbon tax policy," Journal of Central China Normal University, vol. 54, no. 5, pp. 898-909, 2020.

[3] J. J. Fogarty and S. Sagerer, "Exploration externalities and government subsidies: the return to government," Resources Policy, vol. 47, no. 3, pp. 78-86, 2016.

[4] Y. Zhang, Y. Wei, and G. Zhou, "Promoting firms' energysaving behavior: the role of institutional pressures, top management support and financial slack," Energy Policy, vol. 115, no. 1, pp. 230-238, 2018.

[5] M. Liu, Y. Xu, and H. Fu, "Low-carbon supply chain decisionmaking and channel cooperation strategies under the dualchannel background," Soft Science, vol. 33, no. 2, pp. 105-111, 2019.

[6] C. Che, W. P. Luo, and X. L. Qi, "The influence of space and social distance on the online word-of-mouth valence of virtual communities," Soft Science, vol. 31, no. 4, pp. 117-121, 2017.

[7] H. Huang, D. Yang, and Y. Yan, "Pricing decision of closedloop supply chain considering product greenness under fairness preference," Industrial Engineering and Management, vol. 23, no. 6, pp. 162-172, 2018.

[8] S. R. Madani and M. Rasti-Barzoki, "Sustainable supply chain management with pricing, greening and governmental tariffs determining strategies: a game-theoretic approach," Computers \& Industrial Engineering, vol. 105, no. 2, pp. 287-298, 2017.

[9] P. Liu and S.-P. Yi, "Pricing policies of green supply chain considering targeted advertising and product green degree in the big data environment," Journal of Cleaner Production, vol. 164, no. 67, pp. 1614-1622, 2017.

[10] L. Zhang, J. Wang, and J. You, "Consumer environmental awareness and channel coordination with two substitutable products," European Journal of Operational Research, vol. 241, no. 1, pp. 63-73, 2015. 
[11] Z. Basiri and J. Heydari, "A mathematical model for green supply chain coordination with substitutable products," Journal of Cleaner Production, vol. 145, no. 4, pp. 232-249, 2017.

[12] M. Wang, Y. Liu, M. Li et al., "Research on the distribution of emissions reduction benefits from regional cooperation under carbon trading policies," Business Review, vol. 31, no. 2, pp. 264-277, 2019.

[13] M. Wang, L. Zhao, and M. Herty, "Joint replenishment and carbon trading in fresh food supply chains," European Journal of Operational Research, vol. 277, no. 2, pp. 561-573, 2019.

[14] Q. Bai, B. Shi, and J. Xu, "Low-carbon emission reduction operation strategy of the secondary supply chain under risk aversion," Journal of Systems Engineering, vol. 37, no. 3, pp. 86-97, 2019.

[15] K. Chen, q. Cao, X. Wang, and X. Song, "Low-carbon emission reduction operation strategy of the secondary supply chain under risk aversion," Systems Engineering-Theory Methodology Applicatio, vol. 28, no. 2, pp. 338-346, 2019.

[16] X. F. Xu, Z. Lin, and J. Zhu, "DVRPLS with variable neighbourhood region in refined oil distribution," Annals of Operations Research, 2020, In press.

[17] X. Xu, J. Hao, and Y. Zheng, "Multi-objective artificial bee colony algorithm for multi-stage resource leveling problem in sharing logistics network," Computers \& Industrial Engineering, vol. 142, no. 4, p. 106338, 2020.

[18] X. Xu, J. Hao, L. Yu, and Y. Deng, "Fuzzy optimal allocation model for task-resource assignment problem in a collaborative logistics network," IEEE Transactions on Fuzzy Systems, vol. 27, no. 5, pp. 1112-1125, 2019.

[19] X. Xu, Z. Wei, Q. Ji, C. Wang, and G. Gao, "Global renewable energy development: influencing factors, trend predictions and countermeasures," Resources Policy, vol. 63, no. 10, Article ID 101470, 2019.

[20] J. Li, Z. Wang, B. Jiang, and T. Kim, "Coordination strategies in a three-echelon reverse supply chain for economic and social benefit," Applied Mathematical Modelling, vol. 49, no. 3, pp. 599-611, 2017.

[21] X. Pu, L. Gong, and X. Han, "Consumer free riding: coordinating sales effort in a dual-channel supply chain," Electronic Commerce Research and Applications, vol. 22, no. 1, pp. 1-12, 2017.

[22] L. Xu, C. Wang, and J. Zhao, "Decision and coordination in the dual-channel supply chain considering cap-and-trade regulation," Journal of Cleaner Production, vol. 197, no. 17, pp. 551-561, 2018.

[23] B. Zhou, "Research on the structure design and selection strategy of dual-channel supply chain," Management Review, vol. 31, no. 6, pp. 247-257, 2019.

[24] Z. Sun, X. Wang, and H. Zhan, "Game analysis of manufacturers' dual-channel supply chain under different power structures," Chinese Journal of Management Science, vol. 28, no. 9, pp. 154-163, 2020.

[25] W. Wang, F. Wang, and S. Zhang, "Research on coordination contract of dual-channel supply chain considering low-carbon efforts," Management Review, 2020, In press.

[26] X. Liang and C. Wei, "Research on innovation and coordination strategy of dual-channel supply chain under government double subsidy[J/OL]," Industrial Engineering and Management, 2020, In press.

[27] J. Maria, P. Joanna, and V. Zikos, "R\&D subsidies, spillovers, and privatization in mixed markets," Southern Economic Journal, vol. 78, no. 1, pp. 233-255, 2011.
[28] A. Michalsen, "R\&D policy in a vertically related industry," Economics of Innovation \& New Technology, vol. 21, no. 8, pp. 737-751, 2012.

[29] Y. Tong and Y. N. Li, "External intervention or internal coordination? incentives to promote sustainable development through green supply chains," Sustainability, vol. 10, no. 8, pp. 1-21, 2018.

[30] W. Zhang, M. Zhang, W. Zhang, Q. Zhou*, and X. Zhang, "What influences the effectiveness of green logistics policies? A grounded theory analysis," Science of the Total Environment, vol. 714, no. 714, Article ID 136731, 2020.

[31] I. E. Nielsen, S. Majumder, S. S. Sana, and S. Saha, "Comparative analysis of government incentives and game structures on single and two-period green supply chain," Journal of Cleaner Production, vol. 235, no. 93, pp. 1371-1398, 2019.

[32] C. Wang, Q. Zhang, and W. Zhang, "Corporate social responsibility, green supply chain management and firm performance: the moderating role of big-data analytics capability," Research in Transportation Business \& Management, vol. 37, no. 4, Article ID 100557, 2020.

[33] Y. He, Z. Chen, and N. Liao, "the impact mechanism of government subsidies onthe emission reduction decision of green supply chain manufacturers," Chinese Journal of Management Science, 2019, In press.

[34] C. Che, X. L. Qi, W. Q. Ma, and D. X. Shao, "An empirical study on the influencing factors of mobile social network marketing effectiveness," Chinese Journal of Management Science, vol. 25, no. 5, pp. 145-149, 2017.

[35] X. Xia and Q. Zhu, "Research on the influence of different government subsidy strategies on single/double channel recovery," Chinese Journal of Management Science, 2019, In press.

[36] C. Che, W. Q. Ma, and S. F. Cao, "Research on time distance, social distance and the effect of online shopping decision framework," Commercial Research, vol. 2015, no. 9, pp. 130136, 2015.

[37] Y. Zu, L. Chen, and Y. Fan, "Research on low-carbon strategies in supply chain with environmental regulations based on differential game," Journal of Cleaner Production, vol. 177, no. 21, pp. 527-546, 2018.

[38] T. Ye, Z. Guan, and D. Chen, "Dynamic optimization of supply chain considering heterogeneous consumers under carbon policy," Industrial Engineering and Management, vol. 23, no. 1, pp. 14-22, 2018.

[39] T. Li, R. Zhang, S. Zhao, and B. Liu, "Low carbon strategy analysis under revenue-sharing and cost-sharing contracts," Journal of Cleaner Production, vol. 212, no. 67, pp. 1462-1477, 2019.

[40] J.-Y. Chen, S. Dimitrov, and H. Pun, "The impact of government subsidy on supply chains' sustainability innovation," Omega, vol. 86, no. 3, pp. 42-58, 2019.

[41] X. Wen and H. Cheng, "Government subsidy strategy and effect analysis in green supply chain," Chinese Journal of Management, vol. 15, no. 4, pp. 625-632, 2018.

[42] Q. Hu, J. Cao, X. He, and G. Zhou, "Research on production strategy decision of manufacturing enterprises based on government subsidies," Journal of Industrial Engineering and Engineering Management, vol. 31, no. 1, pp. 111-117, 2017.

[43] D. Sun and Y. Yu, "determination of the government's optimal subsidy policy in the green product market," Chinese Journal of Management, vol. 15, no. 1, pp. 118-126, 2018.

[44] X. Cao, Y. Tan, and J. Zhang, "Supply chain carbon emission reduction strategies and coordination based on different government subsidy models," Journal of Central China Normal University, vol. 51, no. 1, pp. 93-99, 2017. 